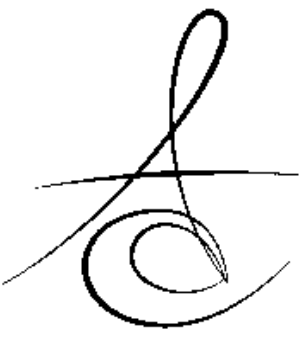

\title{
CAD/CAM SİSTEMİYLE HAZIRLANAN İKİ YÜZLÜ SINIF 2 NANO SERAMİK REZİN İNLEY RESTORASYONLARIN BİR YILLIK KLİNİK PERFORMANSININ DEĞERLENDİRİLMESİ
}

\section{EVALUATION OF THE CLINICAL PERFORMANCE OF CAD/CAM FABRICATED TWO SURFACE CLASS II RESIN NANO CERAMIC INLAY RESTORATIONS}

\author{
Uzm. Dt. Ayşe Tuğçe TUNAÇ* \\ Doç. Dr. Esra UZER ÇELİK*
}

Yrd. Doç. Dr. Bilal YAŞA*

Makale Kodu/Article code: 2856

Makale Gönderilme tarihi: 18.05.2016

Kabul Tarihi: 28.12.2016

\section{$\overline{\mathbf{o z}}$}

Amaç: Bu randomize, kontrollü ve tek merkezli klinik çalışmanın amacı, CAD/CAM sistemiyle hazırlanan iki yüzlü sınıf 2 nano seramik rezin inley restorasyonların 1 yıllık klinik performansını direkt kompozit rezin restorasyonlarla karşılaştırmaktır.

Gereç ve Yöntem: İki yüzlü (MO veya $O D$ ) çürük lezyonu veya değiştirilmesi gereken eski restorasyona sahip 120 adet diş çalışmaya dahil edildi ve rastgele iki gruba ayrildı. Deney grubundaki restorasyonlar CAD/CAM sistemi kullanılarak nano seramik rezin bloklar (Lava Ultimate, 3M ESPE, ABD) ile üretilirken, kontrol grubundaki direkt kompozit rezin restorasyonlar için üç aşamalı etch-and-rinse dentin adeziv sistemiyle (Optibond $\mathrm{FL}$, Kerr, ABD) birlikte posterior nanohibrit bir kompozit rezin (Clearfil Majesty Posterior, Kuraray, Japonya) kullanıldı. Test edilen tüm restoratif materyaller üretici firmaların önerileri doğrultusunda uygulandı. Klinik değerlendirmeler 1 . haftada, 6. ayda ve 1. yilda FDI kriterleri kullanılarak yapıldı. Veriler Friedman's ANOVA ve Mann-Whitney U testleri ile analiz edildi $(\alpha=0.05)$.

Bulgular: Birinci yllın sonunda tüm restorasyonlar ideal veya klinik girişim gerektirmeyen kabul edilebilir klinik performans gösterdi. Tüm kriterlerde iki grup arasında istatistiksel olarak herhangi bir fark gözlenmedi. Sadece 1. yılda direkt kompozit rezin restorasyonların yüzey parlaklığında 2 skoruna doğru anlamlı bir azalma görüldü $(p=0,046)$.

Sonuç: CAD/CAM sistemiyle hazırlanan nano seramik rezin inley restorasyonların 1 yıllık klinik performansı FDI kriterlerine göre başarılı bulunmuştur.

Anahtar kelimeler: CAD/CAM, inleyler, rezin nano seramik, klinik performans

\section{ABSTRACT}

Aim: The aim of this randomized, controlled, single centre clinical trial was to evaluate the one year clinical performance of CAD/CAM fabricated resin nano-ceramic inlay restorations in two surface class II cavities in comparison with direct posterior composite restorations.

Materials and Methods: One hundred and twenty 2-surface (MO/OD) carious lesions or old restorations that needed to be replaced were included and randomly assigned into two groups. The restorations in experimental group were fabricated by a CAD/CAM system with resin nano ceramic blocks (Lava Ultimate, 3M ESPE, USA), while a posterior nanohybrid composite resin (Clearfil Majesty Posterior, Kuraray, Japan) was used for direct posterior composite restorations in control group with a three-step etch \& rinse dentin adhesive system (Optibond FL, Kerr, USA). All tested restorative materials were used according to the manufacturers' instructions. Clinical evaluation was performed after 1 week, 6 months and 1 year according to the FDI criteria. The data were analysed using Friedman's ANOVA and Mann-Whitney $U$ tests $(\alpha=0.05)$.

Results: After 1 year, all restorations were clinically acceptable with no need for clinical attempt. Considering all criteria, the differences between two groups were not statistically significant. Only surface lustre of direct composite restorations significantly reduced to score 2 after 1 year $(p=0.046)$.

Conclusion: The clinical performance of CAD/CAM fabricated resin nano ceramic inlay restorations was found successful according to FDI criteria after 1 year. Key words: CAD/CAM, inlays, resin nano ceramic, clinical performance

\footnotetext{
* İzmir Katip Çelebi Üniversitesi Diş Hekimliği Fakültesi, Restoratif Diş Tedavisi AD
} 
Atatürk Üniv. Diş Hek. Fak. Derg.

] Dent Fac Atatürk Uni

Cilt:27, Sayı:2, Yıl: 2017, Sayfa, 79-87
TUNAÇ, UZER ÇELİK, YAŞA

\section{GİRİŞ}

Günümüzde estetik anlayışının sürekli gelişmesiyle birlikte hastalar arka grup dişleri için de genellikle doğal diş görünümünü ve estetiğini tercih etmektedir. Metal içermeyen diş rengindeki posterior restorasyonlara ilgi ve talebin artması, estetik diş hekimliğinde yeni materyallerin ve tekniklerin gelişmesi için yapılan çalışmaları arttırmıştır. ${ }^{1}$

Direkt posterior kompozit rezin restorasyonlar yaygın olarak kullanılmalarına rağmen, sertleşme sırasında polimerizasyon büzülmesi, kenar defektleri, tüberkül bükülmesi ve çatlaklar, postoperatif hassasiyet, mikrosızıntı, sekonder çürük, anatomik formun tam olarak verilememesi ve ara yüzde parlatmanın yetersiz kalabilmesi gibi problemlere sebep olabilmektedir. Bu problemlere bir çözüm olması amacıyla indirekt restorasyon teknikleri geliştirilmiştir. ${ }^{2}$

Tek diş indirekt restorasyonlar, iyi biyomekanik özelliklere sahip olmakla birlikte, karşıt ve komşu dişlerle uyumlu oklüzal ve aproksimal ilişkiler sağlanarak üretilebilmektedir. Ancak indirekt restorasyonların birden fazla klinik uygulama seans zorunluluğu, alternatif düşüncelerin ortaya çıkmasına sebep olmuştur. Bilgisayar destekli indirekt restorasyonların üretim düşüncesi 1970 'li yılların başında ortaya çıkmıştır. Takip eden yıllarda endüstriyel üretimde yaygın olarak kullanılan bilgisayar destekli tasarım ve bilgisayar destekli üretim (CAD/CAM) teknolojisinin, dental restoratif işlemlerde de kullanılabilirliği üzerine çalışmalar yoğunlaşmıştır. Bu amaçla, CEREC (CEramic REConstruction) (Sirona Dental Systems GmbH, Bensheim, Almanya) sisteminin geliştirilmesi, CAD/CAM teknolojisinin kullanıldığı tek dişe yönelik indirekt adeziv restorasyonların tek seansta uygulamalarının başlangıcı olmuştur. ${ }^{2} \mathrm{Bu}$ sistemin dijital ölçü ve üretim aşamalarında yapılan iyileștirmeler sayesinde kenar ve iç uyumu daha iyi ve klinik başarısı yüksek restorasyonlar elde edilebilmiştir. ${ }^{4-6}$

İnley ve onley restorasyonlar orta büyüklükte ve geniş sınıf 1 ve sınıf 2 kavitelerin tedavisinde kullanılmaktadır. Bu uygulamalarda seramikler yüksek estetik özellikleri, biyouyumlulukları ve çiğneme streslerine direnci nedeniyle tercih edilmektedir. Seramik materyaller kompozit rezin materyallere göre sıkıştırma kuvvetlerine daha dayanıklıdırlar ancak gerilme stresslerine hassastırlar ve kırımaya daha eğimlidirler. Seramikler kompozit rezinlerden daha sert olmalarına ve aşınmaya daha dirençli olmalarına rağmen karşıt dişte normalden daha çok aşınmaya neden olabilirler. ${ }^{7}$

Son zamanlarda geliştirilen nano seramik rezin materyaller, kompozit rezine benzer kolay kullanımları ve seramiğe benzer dayanıklılık ve yüzey bitimi ile avantaj sunmaktadırlar. ${ }^{8}$ Nano seramik teknolojisine dayanan bu materyal hem kompozit rezin hem de cam seramiğe benzer özellikler taşımaktadır. Bu ısıl işlem görmüş materyal rezin ve nano partiküller içeren güçlendirilmiş matriksi ile geleneksel kompozit rezin materyale göre daha sert ve aşınmaya daha dirençlidir. Ayrıca, karşıt dişlerde daha az aşınma meydana getirerek parlaklı̆ını cam seramik gibi uzun süre korur. Firınlama gerektirmemesi ve kompozit rezine benzeyen özellikleri kolay frezlenebilmesine, parlatılabilmesine ve uyumlandırılabilmesine olanak sağlar. Daha az kırılgan olduğundan dolayı, frezleme tankından daha iyi kenar özellikleri ile çıkarlar. Ayrıca aşındırma veya ekleme teknikleri ile ışıkla sertleşen kompozit rezin materyaller kullanılarak ağız içinde tamir edilebilmektedirler. ${ }^{9}$

Literatürde nano seramik rezin materyallerin fiziksel ve mekanik özelliklerini inceleyen in vitro çalışmalar bulunurken, bu materyallerin klinik performansını değerlendiren çalışmalar henüz bildirilmemiştir. Bu nedenle bu araştırmada, CAD/CAM sistemiyle hazırlanan nano seramik rezin inley restorasyonların sınıf 2 mezio-oklüzal (MO) ve oklüzo-distal (OD) kavitelerdeki 1 yıllık klinik performansı direkt kompozit rezin restorasyonlarla karşılaştııılmışıı. Çalışmada test edilen sıfır hipotezi: "Nano seramik rezin inley restorasyonların ve direkt kompozit rezin restorasyonların klinik performansları arasında fark yoktur." şeklindedir.

\section{GEREÇ VE YÖNTEM}

Bu çalışma için etik kurul onayı, İzmir Katip Çelebi Üniversitesi Tıp Fakültesi Klinik Araştırmalar Etik Kurulu'ndan alındı (Etik Kurul Karar Tarih: 12.02.2014 / No:16). Çalışma randomize, kontrollü, paralel grup ve tek merkezli olacak şekilde planlanmış olup, uygulamalar tek araştırmacı tarafindan (ATT) gerçekleştirildi. Her grupta 60 restorasyon olacak şekilde, toplam 120 restorasyon çalışmaya dahil edildi. Çalıșmaya dahil edilme kriterleri;

- Genel sağlık durumunun iyi olması

- 18 yaşından büyük olma

- Periyodik kontrollere gelebilme 
Atatürk Üniv. Diş Hek. Fak. Derg.

J Dent Fac Atatürk Uni

Cilt:27, Sayı:2, Yıl: 2017, Sayfa, 79-87

- Lastik örtü uygulanabilme

- En az 2 tane 2 yüzlü (MO veya OD) çürük veya değiştirilmesi gereken restorasyon içeren diş bulunması

- Çalışmaya dahil edilecek dişlere antagonist ve komşu dişlerin bulunması

\section{Calıșmadan dıșlanma kriterleri;}

- Çalışmada kullanılacak restoratif materyallere allerjisi olma

- Çok kötü ağız hijyeni ve genel sağlığın olması

- Hamile ve emziren bayanlar

- Bruksizm gibi parafonksiyonel alışkanlıkları olan hastalar

- Pulpitis semptomu veya periapikal lezyonu olan dişler

- Ortodontik tedavi gören hastalar

- Belirgin maloklüzyon (çapraz kapanış)

- Şiddetli periodontitis; pürülan eksüda, diş hareketliliği, ileri periodontal ataşman veya kemik kaybı

- Hareketli protez ayağı olan dişler

- Devital veya kanal tedavili dişler

Çalışmaya dahil edilmek üzere muayene edilen 150 gönüllüden, kriterlere uygun 19 ile 45 yaşları arasında (yaş ortalaması 28) olan 44 gönüllü dahil edildi. Tüm hastalardan işlem öncesi, yapılacak uygulamaların aşamaları, sonuçları ve uygulanabilecek alternatif tedavi yöntemlerini içeren imzalı bilgilendirilmiş olur formu alındı. Çalışmaya başlamadan önce iki gözlemci arasında e-calib üzeriden kalibrasyon sağlandı. ${ }^{10}$

Hastaların çalışmaya dahil edilen dişleri uygulanacak restorasyon tipine göre rastgele 2 gruba ayrıldı; A. Direkt kompozit rezin restorasyon grubu (60 restorasyon/44 hasta), B. CAD/CAM sistemiyle hazırlanan nano seramik rezin inley restorasyon grubu (60 restorasyon / 44 hasta) (Şekil 1).

Hastaların dişlerinin hangi gruba dahil edileceğ Microsoft Excel programı kullanılarak rastgelelik tablosuna göre belirlendi. ${ }^{11}$ Restore edilecek dişler FDI sistemine göre olan numaraları doğrultusunda randomizasyon tablosunda küçükten büyüğe doğru sıralandı. Dişler randomizasyon tablosuna göre rastgele deney ve kontrol grubuna atandı.

Her grupta en az bir diş yer aldı. Her hastada, her grup için eşit sayıda olmak üzere, toplamda en az 2 ve en fazla 6 diş çalışmaya dahil edildi. Hastalardan ağız hijyeni (plak indeksi ve diş fırçalama sıklığı), alışkanlıkları (sigara kullanımı), diyetleri (renklendirici
TUNAÇ, UZER ÇELİK, YAŞA

içecek kullanım sıklığı ve asitli içecek kullanım sıklığı), restore edilecek dişlerin hassasiyet durumu ile ilgili veriler toplandı. Diş yüzeyi temizliği ve ağız hijyen eğitimini içeren rutin profesyonel ağız bakımı yapıldı. Dişlerin başlangıç fotoğrafları ağız içi fotoğraf aynası yardımıyla dijital fotoğraf makinesi (Nikon D7100, Tokyo, Japonya) kullanılarak alındı. Hastaların çalışmaya dâhil edilecek dişlerinin periapikal dokuları panoramik radyografilerle başlangıçta kontrol edildi. Restore edilecek dişlerin renkleri klasik Vita renk skalasına göre gözle muayene edilerek belirlendi.

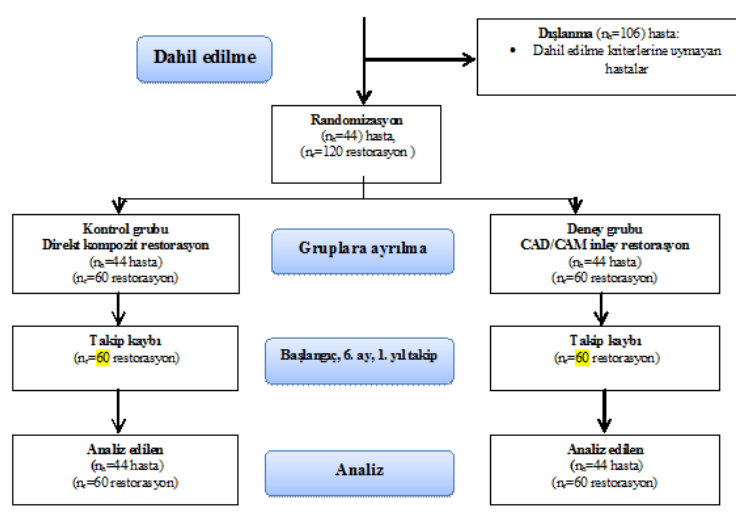

Şekil 1. Çalışma akış şeması.

\section{Direkt kompozit rezin restorasyon uygulanan grup (kontrol grubu):}

Kavite preparasyonunun sınırları hazırlandıktan sonra primer ve varsa sekonder çürük temizlendi. İhtiyaç duyulduğunda hastaya lokal anestezi (Maxicaine Ampul, VEM İlaç, İstanbul, Türkiye) uygulandı. Çürük dokusu ve eski restorasyonlar düşük devirde karbit frezlerle (MEDIN, Nové Město na Moravě, Çek Cumhuriyeti) uzaklaştırıldı. Kavite tabanındaki renkli ama sert dentin dokusu bırakıldı. Desteksiz mine kenarları uzaklaştırıldı. Karşılıklı kavite duvarları paralel veya çok az oklüzale doğru daralan şekilde hazırlandı. Kavite iç açıları yuvarlaklaştırıldı. Tüm kavite kenarları mine üzerinde sonlandırıldı ve bizotaj yapılmadı. Tüm pulpaya bakan yüzeyler dentinde sonlandırıldı. Sadece meziyo-oklüzal veya oklüzo-distal olarak bir bütün şeklinde hazırlanacak kaviteler çalışmaya dahil edildi. Isthmus eğer tüberküller arası mesafesinin 2/3'ünden fazla ise, duvarlar preparasyon öncesinde $2 \mathrm{~mm}$ 'den ince, veya preparasyondan sonra $1,5 \mathrm{~mm}$ 'den ince ise bu dişlerin çalışmadan çıkarılması planlandı ancak böyle bir durumla karşılaşılmadı.

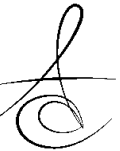


Atatürk Üniv. Diş Hek. Fak. Derg.

J Dent Fac Atatürk Uni

Cilt:27, Sayı:2, Yıl: 2017, Sayfa, 79-87

Dişlerin restorasyon öncesi izolasyonu lastik örtü kullanılarak gerçekleştirildi. Kalan dentin kalınlığının 0,5 mm'nin altında olduğu alanlara kalsiyum hidroksit (Dycal, Dentsply, Milford, DE, ABD) uygulandı. Pulpanın açığa çıktığı dişlerin çalışmadan çıkarılması planlandı ancak böyle bir durumla karşılaşılmadı. Kalsiyum hidroksit uygulanan kavitelere rezin modifiye cam iyonomer liner (Vitrebond Plus, 3M ESPE, St. Paul, MN, ABD) uygulandı (Tablo 1).
TUNAÇ, UZER ÇELİK, YAŞA

Tablo 1. Çalışmada uygulanan restoratif materyaller

\begin{tabular}{|c|c|c|c|}
\hline Materyal & Üretici Firma & İçerik & Lot Numarası \\
\hline Clearfil Majesty Posterior & Kuraray, & \multirow{2}{*}{$\begin{array}{l}\text { BIS-GMA, TEGDMA, hidrofobik aromatik dimetakrilat, } \\
\text { silanize cam seramik, alumina mikro doldurucular, silika } \\
\text { partikülleri, kamforokinon }\end{array}$} & A2: AR0002 \\
\hline Kompozit Rezin & $\begin{array}{l}\text { Okayama, } \\
\text { Japonya }\end{array}$ & & A3: 0127AA \\
\hline Lava Ultimate Nano Seramik & 3M ESPE, St. & \multirow{12}{*}{$\begin{array}{l}\text { Silika nanomerleri, zirkonya nanomerleri, silanize edici ajan, } \\
\text { rezin matriks }\end{array}$} & A2 HT: N525442 \\
\hline \multirow[t]{11}{*}{ Rezin CAD/CAM Restoratif } & \multirow{11}{*}{ Paul, MN, ABD } & & A2 HT: N538336 \\
\hline & & & A2 HT: N525442 \\
\hline & & & A2 HT: N628830 \\
\hline & & & A2 LT: N554521 \\
\hline & & & A3 HT: N557733 \\
\hline & & & A3 HT: N557733 \\
\hline & & & A3 HT: N557733 \\
\hline & & & A3 LT: N548041 \\
\hline & & & A2 LT: N554521 \\
\hline & & & A3 LT: N548041 \\
\hline & & & A3 LT: N548041 \\
\hline Optibond FL Etch-and-rinse & Kerr, Orange, & Primer: Alkil dimetakrilat rezin etil alkol, su & Primer: 4633039 \\
\hline Dentin Adeziv Sistem & $A B D$ & $\begin{array}{l}\text { Bağlayıc Ajan: HEMA, hidroksipropanedil bismetakrilat, } \\
\text { alkali florosilikat }\end{array}$ & Bağlayıcı Ajan: 4689426 \\
\hline \multirow[t]{2}{*}{$\begin{array}{l}\text { Vitrebond Plus Rezin Modifiye } \\
\text { Cam İyonomer Liner }\end{array}$} & \multirow[t]{2}{*}{$\begin{array}{l}\text { 3M ESPE, St. } \\
\text { Paul, MN, ABD }\end{array}$} & $\begin{array}{l}\text { Likit: Rezin modifiye polialkenoik asit, HEMA, su ve } \\
\text { başlatıcılar }\end{array}$ & \multirow[t]{2}{*}{ N480593 } \\
\hline & & $\begin{array}{l}\text { Toz: HEMA, BIS-GMA, su, başlatıcılar ve radyoopak } \\
\text { floroaluminosilikat }\end{array}$ & \\
\hline $\begin{array}{l}\text { RelyX Ultimate Dual Cure } \\
\text { Yapıştırma Simanı }\end{array}$ & $\begin{array}{l}\text { 3M ESPE, St. } \\
\text { Paul, MN, ABD }\end{array}$ & $\begin{array}{l}\text { Cam tozu, TEGDMA, silanize silika, oksit cam kimyasalları, } \\
\text { sodyum persülfat, tert-butyl peroxy-3,5,5-trimetilheksanoat }\end{array}$ & 525320 \\
\hline
\end{tabular}

Kaviteler bölümlü matris (Palodent Matris Sistemi / Standard Kit, DENTSPLY, Milford, DE, ABD) ve tahta kamalar kullanılarak restore edildi. Kompozit rezin materyalin dişe bağlanması için üç aşamalı etchand-rinse dentin adeziv sistem (Optibond FL, Kerr, Orange, $C A, A B D$ ) kullanıldı. Tüm kavite 15 sn $\% 37,5$ 'lik fosforik asit (Gel Etchant, Kerr) ile pürüzlendirildi ve hava su spreyi ile en az 15 sn yıkanarak temizlendi. Asitleme sonrası yüzey hafif nemli bırakıldı ve primer 15 sn boyunca hafif ovalama hareketi ile yüzeye uygulandı ve çözücüsünün uzaklaşması için 5 sn süreyle hafif hava ile kurutuldu. Bağlayıcı ajan aplikatör ile kaviteye hafifçe ovalama hareketi ile 15 sn boyunca uygulandı ve göllenmeyi engelleyecek şekilde hava ile yayıldı. LED ışık cihazı (Valo Cordless, Ultradent, South Jordan, UT, ABD) yardımıyla 10 sn süre ile sertleştirildi. Kavitelere kompozit rezin (Clearfil Majesty Posterior, Kuraray, Tokyo, Japonya) tabakalar halinde yerleştirildi ve her tabaka 10 sn ışıkla sertleştirildi.
Lastik örtü çıkarıldıktan ve oklüzyon kontrolü yapıldıktan sonra bitirme ve parlatma işlemleri sarı kuşak elmas alev uçlu ve labut frezlerle, parlatma diskleri (Sof-Lex, 3M ESPE, ) ve elmas partikül içeren parlatma lastikleri (Jazz Polishers, SS White Dental, Lakewood, $\mathrm{NJ}, A B D$ ) ile gerçekleştirildi. Elmas partikül içeren parlatma pastası (Intensiv UniglossPaste, Intensiv SA, Montagnola, İsviçre) kıl fırça yardımı ile uygulandı. Ara yüzeylerde kontağın altındaki alanlar ara yüz zımparaları (Coltene, Altstätten, İsviçre) ile düzeltildi. 
Atatürk Üniv. Diş Hek. Fak. Derg.

] Dent Fac Atatürk Uni

Cilt:27, Sayı:2, Yıl: 2017, Sayfa, 79-87
TUNAÇ, UZER ÇELİK, YAŞA çıkarılması planlandı ancak böyle bir durumla karşılaşılmadı. Kavitelerdeki düzensiz alanları ortadan kaldırmak amacıyla ve kaide materyali olarak rezin modifiye cam iyonomer liner uygulandı.

CAD/CAM restorasyonlar CEREC AC sistemi (Sirona, Bensheim, Almanya) kullanılarak hazırlandı. Preparasyonun ölçüsü CAD/CAM sistemine bağlı optik ölçü kamerası (Omnicam, Sirona, Almanya) ile alındı. Restorasyonun dizaynı CEREC SW 4.3 (Sirona) ara yüzü kullanılarak gerçekleştirildi. CAD/CAM sisteminin üretim cihazına (CEREC MC-XL, Sirona) seçilen ilgili bloklar (Lava Ultimate, 3M ESPE) yerleştirildi ve restorasyonlar bu cihazda frezlenerek üretildi.

İnley restorasyonlar parlatma diskleri (Sof-Lex Discs), elmas partikül içeren parlatma lastikleri (Jazz Polishers) ve elmas partikül içeren parlatma pastasıyla (Intensiv UniglossPaste) parlatıldı.

Dişlerin simantasyon öncesi izolasyonu lastik örtü kullanılarak gerçekleştirildi. İnleyin simante edilecek yüzeyi $30 \mu m^{\prime}$ lik alüminyum oksit kum (CoJet Sistem, 3M ESPE, Seefeld, Almanya) ile 2 bar basınçta tamamen matlaşana kadar kumlandı ve alkol ile temizlenerek hava ile kurutuldu. Restorasyonun is yüzeyine seramik primeri (Rely-X Ceramic Primer, 3M ESPE) bir aplikatör yardımı ile uygulandı ve kurumaya bırakıldı. Kavite yüzeyi 15 sn boyunca \%.37,5'luk fosforik asit (Gel Etchant, Kerr) ile pürüzlendirilip 15 sn boyunca yıkandı ve kurutuldu. Asitleme sonrası yüzey hafif nemli bırakıldı ve primer 15 sn boyunca yüzeye hafif ovalama hareketi ile uygulanıp çözücüsünün uzaklaşması için 5 sn süreyle hava ile kurutuldu. Bağlayıcı ajan aplikatör ile kaviteye 15 sn boyunca hafif ovalama hareketi ile uygulandı ve göllenmeyi engelleyecek şekilde hava ile yayıldı. LED ışık cihazı yardımıyla 10 sn süre ile sertleştirildi. Restorasyonun simante edilecek yüzeyine bir aplikatör yardımı ile bağlayıcı ajan (Optibond FL) 20 sn boyunca ovalama hareketi ile uygulandı ve 5 sn boyunca hava ile yayıldı. Dual-cure adeziv siman (Rely-X Ultimate, 3M ESPE) tüm kavite yüzeylerine ve restorasyonun simante edilecek yüzeyine uygulandı ve restorasyon diş yüzeyine yerleştirildi. Yerleştirmeden sonra artık simanlar aplikatör ve diş ipi ile temizlendi ve restorasyon kenarları gliserin jel ile kaplandı. Siman sertleşene kadar restorasyonun stabilizasyonu sağlandı. Toplamda en az 60 sn olmak üzere her yüzeyden 20'şer sn boyunca LED ışık cihazı ile siman sertleştirildi. Karıştırma süresinden itibaren $6 \mathrm{dk}$ boyunca tamamen polimerizasyon için beklendi, daha sonra lastik örtü çıkartılarak oklüzal ilişkiler kontrol edildi. Sarı kuşaklı elmas frezlerle düzeltilen yüzeyler ve siman ara yüzeyi parlatma diskleri (Sof-Lex Discs) ve parlatma pastası (Intensiv UniglossPaste) ile parlatıldı.

\section{Restorasyonların Değerlendirilmesi}

Klinik araştırma süresinde hastalar 1 hafta, 6 ay ve 1 yıl performanslarının incelenmesi amacıyla bu dönemlerde kontrole çağırıldı. Restorasyonların değerlendirilmesinde FDI Kriterleri kullanıldı. ${ }^{11} \mathrm{Bu}$ kriterlere göre restorasyonlar, klinik uygulamaları yapan hekim dışındaki deneyimli iki gözlemci tarafından 3 alanda değerlendirildi: 1. Estetik (yüzey parlaklığı, yüzey renklenmesi, kenar renklenmesi, renk uyumu ve translü sentlik, anatomik form), 2. Fonksiyonel (materyalde kırık veya retansiyon problemi, kenar uyumu, aşınma, kontak, hasta görüşü), 3. Biyolojik (postoperatif hassasiyet ve vitalite, çürük oluşumu, erozyon veya abrazyon, diş bütünlüğü, periodontal cevap, komşu mukoza, ağız ve genel sağlık). Her kriter klinik olarak çok iyi, iyi, yeterli, yeterli olmayan ve başarısız olarak 1 ile 5 arasında skorlanarak değerlendirildi.

\section{İstatistiksel Değerlendirme}

İstatistiksel analizler için IBM SPSS Statistics-22 (IBM Corporation, New York, ABD) programı kullanıldı. Tüm kriterler için her materyalin farklı değerlendirme periyotlarında elde ettiği skorlar Friedman's ANOVA ve Mann Whitney-U testleri kullanılarak analiz edildi. Her bir kriter için iki restoratif materyal arasındaki farklar her değerlendirme periyodunda Mann-Whitney $U$ testi ile hesaplandı. Tüm testlerde $\alpha=0,05$ olarak kabul edildi.

\section{BULGULAR}

Gözlemciler arası uyum Cohen's Kappa testine göre 0,80 olarak bulunurken, gözlemci içi uyum birinci gözlemci için 0,85 , ikinci gözlemci için 0,83 olarak hesaplandı.

Çalışmamıza yaş ortalamaları 28 olan $21^{\prime} i$ bayan ve 23 'ü erkek olmak üzere toplam 44 gönüllü katıldı. Kırk dört hastada 65 premolar, 55 molar, toplam 120 dişe restorasyon uygulandı (Tablo 2). Otuz iki hastaya 2'şer restorasyon, 11 hastaya 4'er restoras yon, 2 hastaya ise 6'şar restorasyon uygulandı. Çalışmaya dahil edilen hastaların tamamı restoratif tedavilerini tamamlamıştır. Başlangıç, 6. ay ve 1 . yıl sonunda tüm hastalar kontrol edilebilmiştir.

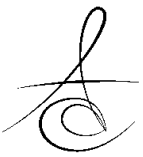


Tablo 2. Değerlendirme kriterleri ve lezyon sayıları.

\begin{tabular}{llc}
\hline & Değerlendirme yöntemi & $\begin{array}{l}\text { Lezyon sayısı } \\
\text { Nano seramik rezin } \\
\text { (RNS)/ } \\
\text { Kompozit (K) }\end{array}$ \\
\hline Operasyon öncesi hassasiyet & $\begin{array}{l}\text { Anamnez ve hava basıncılla 3 sn boyunca } \\
\text { Yok }\end{array}$ & $45 / 40$ \\
Uyarılmıs & & $15 / 20$ \\
Kavite derinliği & Preparasyon sonrası gözle muayene & $3 / 6$ \\
Siğ & Dentine penetrasyon $\leq 1 \mathrm{~mm}$ & $27 / 32$ \\
Normal & Dentie penetrasyon $>1 \mathrm{~mm}$, kalınlı̆ı̆ı & \\
Derin & 2mm & $30 / 22$ \\
Diş dağılımı & Kalan dentin kalınlığı $\leq 2 \mathrm{~mm}$ & Üst-alt çene / Üst-alt çene \\
Premolar & & $19-12 / 19-15$ \\
Molar & & $17-12 / 13-13$ \\
Liner uygulaması & & $60 / 15$ \\
Var & & $0 / 45$ \\
Yok & & $20 / 15$ \\
Kalsiyum hidroksit uygulanması & & $40 / 45$ \\
Var & & \\
Yok & & \\
\hline
\end{tabular}

Çalışmaya katılan hastalarda tedavi başarısı ve klinik performans açısından çalışma grupları arasında fark yaratabileceğini düşündüğümüz tedavi sırasında kaydedilen operasyon öncesi hassasiyet, kavite derinliği, kalsiyum hidroksit ve liner uygulanmasının karşılaştırıldı̆ı değerlendirmede; liner uygulanmasının nano seramik rezin inley grubunda daha fazla olduğu gözlenmiştir $(p<0,05)$. Diğer kriterler açısından direkt kompozit rezin restorasyon ve nano seramik rezin inley grupları arasında istatistiksel olarak anlamlı farklılık gözlenmedi.

Değerlendirme kriterlerinin iki grup arasındaki farklılığının incelendiği Mann Whitney $U$ testine göre analiz sonuçları Tablo 3'de verilmiştir. Kriterlerin hiçbirinde başlangıçta ve takip süresi boyunca gruplar arasında istatistiksel olarak anlamlı bir fark bulunamamıştır

Tüm kriterlerde başlangıçta ve 6 . ay kontollerinde istatistiksel olarak anlamlı bir değişim görülmemiştir. Kompozit rezin restorasyonların yüzey parlaklığında 6. ay ile 1. yıl arasında istatistiksel olarak anlamlı bir azalma görülmüştür $(p=0,046)$. Yüzey parlaklığı kriterinde, kompozit restorasyon grubunda 6 . ayda hiç 2 skoru bulunmazken, 1. yılda 4 restorasyon 2 skoru almıştır (Resim 1-4).

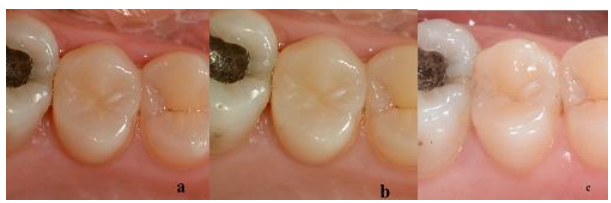

Resim 1. 15 numaralı dişe OD yönde uygulanmış 1 . yılda yüzey parlaklığı kriterinden 2 skoru alan bir kompozit restorasyon, a) Başlangıç b) 6. ay c) 1 . Yıl

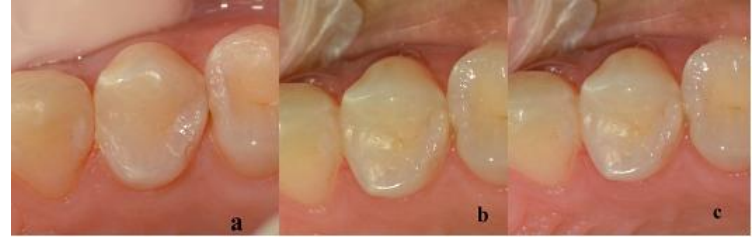

Resim 2. 24 numaralı dişe MO yönde uygulanmış tüm kriterlerden 1 skoru alan kompozit restorasyon, a) Başlangıc b) 6. ay c) 1. yıl

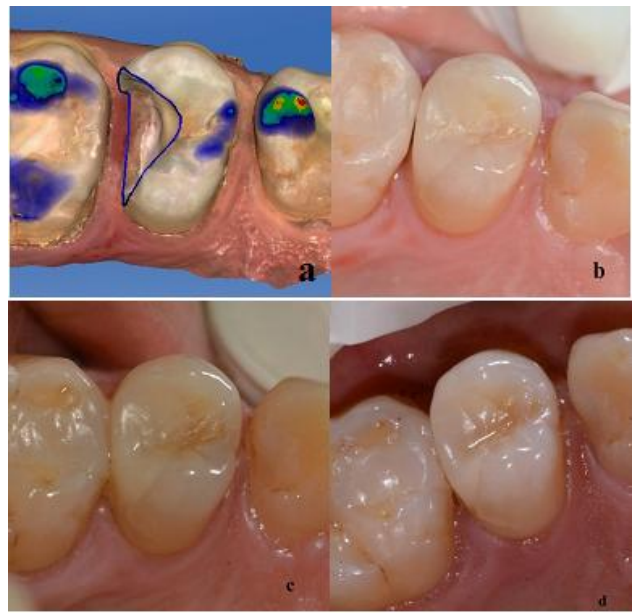

Resim 3. 15 numaralı dişe OD yönde uygulanmış 6 . ayda ve 1. yılda kenar renklenmesi kriterinden 2 skoru alan bir inley restorasyon, a) Kavitenin optik ölçüsü b) Başlangıç c) 6. ay d) 1. yll.

\section{TARTIŞMA}

İndirekt restorasyonlarla anatomik formlarının ağız dışında hazırlanması ve ağız dışında parlatılmaları nedeniyle direkt restorasyonlara göre daha iyi estetik

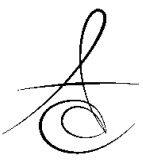


Atatürk Üniv. Diş Hek. Fak. Derg.

J Dent Fac Atatürk Uni

Cilt:27, Sayı:2, Yıl: 2017, Sayfa, 79-87

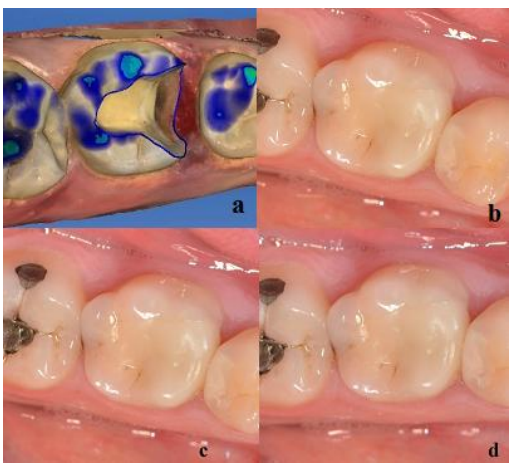

Resim 4. 36 numaralı dişe MO yönde uygulanmış tüm kriterlerden 1 skoru alan bir inley restorasyon, a) Kavitenin optik ölçüsü b) Başlangıç c) 6. ay d) 1. yıl

sonuçlar elde etmek daha kolaydır. Diş hekimliğinde indirekt restorasyonların uygulama süresini kısaltmak ve yapım aşamalarını kolaylaştırmak için yeni teknikler ve materyaller geliştirilmiştir. CAD/CAM sistemleri indirekt restorasyonların yapım aşamalarını basitleştirilerek daha iyi materyallerin kullanılabilmesine imkan sağlanmıştır. ${ }^{13,14}$ CAD/CAM sistemlerinin amacı, temel olarak yapım aşamasında materyalin özelliklerini etkileyebilecek hataların ortadan kaldırımasıdır. Rezin içeren CAD/CAM bloklar endüstriyel olarak yüksek ISI
TUNAÇ, UZER ÇELİK, YAŞA

ve basınçta, standardize şekilde polimerize edilmiş olduğundan geleneksel olarak polimerize edilen materyallere kiyasla daha iyi mekanik ve fiziksel özelliklere sahiptir. ${ }^{15-17}$ Nano seramik rezin hibrit bloklar mekanik özelliklerinin bir sonucu olarak karşıt dişi daha az aşındırırken, restorasyonun kendisindeki kayıp, cam seramiklere göre daha fazla olmaktadır. Kompozit rezine göre ise renklenme ve aşınma daha az görülmektedir. ${ }^{18,19}$ Bu çalışmada hazırlanan inley restorasyonlar için nano seramik rezin bloklar belirtilen özelliklerinden dolayı tercih edilmiştir.

Çalışmamızda test edilen sıfır hipotezi kabul edilmiştir. Nano seramik rezin inley restorasyonlar ile direkt kompozit rezin restorasyonların bir yıllık klinik performansı arasında fark bulunmamıştır.

Direkt kompozit rezin restorasyonları nano seramik rezin restorasyonlarla karşılaştıran klinik çalışma bulunmasa da, direkt ve indirekt kompozit rezin restorasyonları karşılaştıran birçok klinik çalışma bulunmaktadır. ${ }^{20-22}$ Bu çalışmalarda direkt kompozit rezin ve indirekt kompozit rezin inleyler posterior bölgede tatmin edici klinik performans göstermiştir ve aralarında karşılaştırma yapıldığında istatistiksel olarak anlamlı olmayan farklar görülmekte veya hiç fark görülmemektedir.

Tablo 3. FDI kriterlerine göre restorasyonların skor dağıımı.

\begin{tabular}{|c|c|c|c|c|c|c|c|c|c|c|c|c|}
\hline & & \multicolumn{3}{|c|}{ Direkt Kompozit Restorasyon } & \multicolumn{4}{|c|}{$\begin{array}{c}\text { Indirekt Nano Seramik Rezin } \\
\text { Restorasyon }\end{array}$} & \multicolumn{4}{|c|}{ p değeri } \\
\hline & & $\begin{array}{c}\text { Başlangıç } \\
\text { skorları } \\
1 / 2 / 3 / 4 / 5 \\
\end{array}$ & $\begin{array}{c}6 \text { ay sonraki } \\
\text { skorlar } \\
1 / 2 / 3 / 4 / 5 \\
\end{array}$ & $\begin{array}{c}1 \text { yıl sonraki } \\
\text { skorlar } \\
1 / 2 / 3 / 4 / 5 \\
\end{array}$ & $\begin{array}{c}\text { Klinik olarak } \\
\text { kabul edilen } \\
\text { restorasyonlar }\end{array}$ & $\begin{array}{c}\text { Başlangıç } \\
\text { skorları } \\
1 / 2 / 3 / 4 / 5 \\
\end{array}$ & $\begin{array}{c}6 \text { ay sonraki } \\
\text { skorlar } \\
1 / 2 / 3 / 4 / 5 \\
\end{array}$ & $\begin{array}{c}1 \text { yıl sonraki } \\
\text { skorlar } \\
1 / 2 / 3 / 4 / 5 \\
\end{array}$ & $\begin{array}{c}\text { Klinik olarak } \\
\text { kabul edilen } \\
\text { restorasyonlar }\end{array}$ & $\begin{array}{l}\text { CM/LU } \\
\text { 1. hafta }\end{array}$ & $\begin{array}{l}\text { CM/LU } \\
6 . \text { ay }\end{array}$ & $\begin{array}{l}\text { CM/LU } \\
\text { 1. yil }\end{array}$ \\
\hline \multirow{5}{*}{ 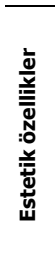 } & $\begin{array}{c}\text { Yüzey } \\
\text { parlaklığı }\end{array}$ & $\begin{array}{c}60 / 0 / 0 / 0 / \\
0\end{array}$ & $60 / 0 / 0 / 0 / 0$ & $56 / 4 / 0 / 0 / 0$ & $\% 100$ & $60 / 0 / 0 / 0 / 0$ & $60 / 0 / 0 / 0 / 0$ & $59 / 1 / 0 / 0 / 0$ & $\% 100$ & 1,000 & 1,000 & 0,172 \\
\hline & $\begin{array}{l}\text { Yüzey } \\
\text { renklenmesi }\end{array}$ & $\begin{array}{c}60 / 0 / 0 / 0 / \\
0\end{array}$ & $59 / 1 / 0 / 0 / 0$ & $58 / 2 / 0 / 0 / 0$ & $\% 100$ & $60 / 0 / 0 / 0 / 0$ & $60 / 0 / 0 / 0 / 0$ & $60 / 0 / 0 / 0 / 0$ & $\% 100$ & 1,000 & 0,317 & 0,156 \\
\hline & $\begin{array}{l}\text { Kenar } \\
\text { renklenmesi }\end{array}$ & $\begin{array}{c}60 / 0 / 0 / 0 / \\
0\end{array}$ & $59 / 1 / 0 / 0 / 0$ & $57 / 3 / 0 / 0 / 0$ & $\% 100$ & $60 / 0 / 0 / 0 / 0$ & $59 / 1 / 0 / 0 / 0$ & $59 / 1 / 0 / 0 / 0$ & $\% 100$ & 1,000 & 1,000 & 0,311 \\
\hline & $\begin{array}{c}\text { Renk uyumu } \\
\text { ve translüsensi }\end{array}$ & $\begin{array}{c}60 / 0 / 0 / 0 / \\
0\end{array}$ & $60 / 0 / 0 / 0 / 0$ & $60 / 0 / 0 / 0 / 0$ & $\% 100$ & $60 / 0 / 0 / 0 / 0$ & $60 / 0 / 0 / 0 / 0$ & $60 / 0 / 0 / 0 / 0$ & $\% 100$ & 1,000 & 1,000 & 1,000 \\
\hline & $\begin{array}{l}\text { Estetik } \\
\text { anatomik form }\end{array}$ & $\begin{array}{c}60 / 0 / 0 / 0 / \\
0\end{array}$ & $60 / 0 / 0 / 0 / 0$ & $59 / 1 / 0 / 0 / 0$ & $\% 100$ & $60 / 0 / 0 / 0 / 0$ & $60 / 0 / 0 / 0 / 0$ & $59 / 1 / 0 / 0 / 0$ & $\% 100$ & 1,000 & 1,000 & 1,000 \\
\hline \multirow{5}{*}{ 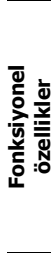 } & Retansiyon & $\begin{array}{c}60 / 0 / 0 / 0 / \\
0\end{array}$ & $60 / 0 / 0 / 0 / 0$ & $60 / 0 / 0 / 0 / 0$ & $\% 100$ & $60 / 0 / 0 / 0 / 0$ & $60 / 0 / 0 / 0 / 0$ & $60 / 0 / 0 / 0 / 0$ & $\% 100$ & 1,000 & 1,000 & 1,000 \\
\hline & Kenar uyumu & $\begin{array}{c}60 / 0 / 0 / 0 / \\
0\end{array}$ & $59 / 1 / 0 / 0 / 0$ & $59 / 1 / 0 / 0 / 0$ & $\% 100$ & $60 / 0 / 0 / 0 / 0$ & $60 / 0 / 0 / 0 / 0$ & $60 / 0 / 0 / 0 / 0$ & $\% 100$ & 1,000 & 0,317 & 0,317 \\
\hline & $\begin{array}{l}\text { Oklüzal kontur } \\
\text { ve aşınma }\end{array}$ & $\begin{array}{c}60 / 0 / 0 / 0 / \\
0\end{array}$ & $60 / 0 / 0 / 0 / 0$ & $60 / 0 / 0 / 0 / 0$ & $\% 100$ & $60 / 0 / 0 / 0 / 0$ & $60 / 0 / 0 / 0 / 0$ & $60 / 0 / 0 / 0 / 0$ & $\% 100$ & 1,000 & 1,000 & 1,000 \\
\hline & Hasta görüşü & $\begin{array}{c}60 / 0 / 0 / 0 / \\
0\end{array}$ & $60 / 0 / 0 / 0 / 0$ & $60 / 0 / 0 / 0 / 0$ & $\% 100$ & $60 / 0 / 0 / 0 / 0$ & $60 / 0 / 0 / 0 / 0$ & $60 / 0 / 0 / 0 / 0$ & $\% 100$ & 1,000 & 1,000 & 1,000 \\
\hline & $\begin{array}{l}\text { Kontak ve } \\
\text { kontur }\end{array}$ & $\begin{array}{c}60 / 0 / 0 / 0 / \\
0\end{array}$ & $60 / 0 / 0 / 0 / 0$ & $60 / 0 / 0 / 0 / 0$ & $\% 100$ & $60 / 0 / 0 / 0 / 0$ & $60 / 0 / 0 / 0 / 0$ & $60 / 0 / 0 / 0 / 0$ & $\% 100$ & 1,000 & 1,000 & 1,000 \\
\hline \multirow{7}{*}{ 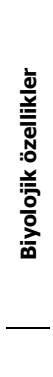 } & $\begin{array}{l}\text { Postop } \\
\text { hassasiyet ve } \\
\text { vitalite }\end{array}$ & $\begin{array}{c}60 / 0 / 0 / 0 / \\
0\end{array}$ & $60 / 0 / 0 / 0 / 0$ & $59 / 1 / 0 / 0 / 0$ & $\% 100$ & $60 / 0 / 0 / 0 / 0$ & $60 / 0 / 0 / 0 / 0$ & $60 / 0 / 0 / 0 / 0$ & $\% 100$ & 1,000 & 1,000 & 0,317 \\
\hline & Çürük, erezyon & $\begin{array}{c}60 / 0 / 0 / 0 / \\
0\end{array}$ & $60 / 0 / 0 / 0 / 0$ & $60 / 0 / 0 / 0 / 0$ & $\% 100$ & $60 / 0 / 0 / 0 / 0$ & $60 / 0 / 0 / 0 / 0$ & $60 / 0 / 0 / 0 / 0$ & $\% 100$ & 1,000 & 1,000 & 1,000 \\
\hline & Diş bütünlüğü & $\begin{array}{c}60 / 0 / 0 / 0 / \\
0\end{array}$ & $60 / 0 / 0 / 0 / 0$ & $60 / 0 / 0 / 0 / 0$ & $\% 100$ & $60 / 0 / 0 / 0 / 0$ & $60 / 0 / 0 / 0 / 0$ & $60 / 0 / 0 / 0 / 0$ & $\% 100$ & 1,000 & 1,000 & 1,000 \\
\hline & $\begin{array}{l}\text { Periyodontal } \\
\text { cevap }\end{array}$ & $\begin{array}{c}60 / 0 / 0 / 0 / \\
0\end{array}$ & $60 / 0 / 0 / 0 / 0$ & $59 / 1 / 0 / 0 / 0$ & $\% 100$ & $60 / 0 / 0 / 0 / 0$ & $60 / 0 / 0 / 0 / 0$ & $59 / 1 / 0 / 0 / 0$ & $\% 100$ & 1,000 & 1,000 & 1,000 \\
\hline & Komşu mukoza & $\begin{array}{c}60 / 0 / 0 / 0 / \\
0\end{array}$ & $60 / 0 / 0 / 0 / 0$ & $60 / 0 / 0 / 0 / 0$ & $\% 100$ & $60 / 0 / 0 / 0 / 0$ & $60 / 0 / 0 / 0 / 0$ & $60 / 0 / 0 / 0 / 0$ & $\% 100$ & 1,000 & 1,000 & 1,000 \\
\hline & $\begin{array}{l}\text { Ağız ve genel } \\
\text { sağlık }\end{array}$ & $\begin{array}{c}60 / 0 / 0 / 0 / \\
0\end{array}$ & $60 / 0 / 0 / 0 / 0$ & $60 / 0 / 0 / 0 / 0$ & $\% 100$ & $60 / 0 / 0 / 0 / 0$ & $60 / 0 / 0 / 0 / 0$ & $60 / 0 / 0 / 0 / 0$ & $\% 100$ & 1,000 & 1,000 & 1,000 \\
\hline & $\begin{array}{c}\text { Toplam } \\
\text { başarı oranı }\end{array}$ & & & & $\% 100$ & & & & $\% 100$ & & & \\
\hline
\end{tabular}


Atatürk Üniv. Diş Hek. Fak. Derg.

J Dent Fac Atatürk Uni

Cilt:27, Sayı:2, Yıl: 2017, Sayfa, 79-87
TUNAÇ, UZER ÇELİK, YAŞA
Çalışmamızda, nano seramik rezin inley restorasyonlar ile direkt kompozit rezin restorasyonlar 1 yıl sonunda \%100 klinik başarı göstermiştir. Çetin ve ark. ${ }^{23}$ indirekt kompozit rezin inley restorasyonlar ile direkt kompozit rezin restorasyonların klinik performanslarını inceledikleri çalışmalarında, 5 yıl sonundaki başarı oranlarını sırasıyla \%97,5 ve \%98,4 olarak bulmuşlardır. Dukic ve ark. ${ }^{24}$ indirekt kompozit rezin restorasyonların 3 yıllık klinik performanslarını inceledikleri çalışmada başarı oranını \%100 olarak bulmuşlardır. Lange ve Pfeiffer, ${ }^{25}$ uyguladıkları seramik inleyler ile direkt posterior hibrit kompozit rezin restorasyonları karşılaştırdıkları çalışmalarında, başarı oranını 57 ay sonra seramik inleyler için \%94, kompozit rezin restorasyonlar için \%93 olarak bularak iki restorasyon tipi arasında istatistiksel olarak anlamlı bir fark bildirmemişlerdir. Fasbinder ve ark., ${ }^{26}$ CAD/CAM ile üretilen kompozit rezin ve seramik inleylerin klinik performanslarını inceledikleri 3 yıllık çalışmanın sonucunda, kompozit rezin CAD/CAM inleylerin seramik CAD/CAM inleyler kadar iyi performans gösterdiklerini belirtmişlerdir. Bununla birlikte Fasbinder, ${ }^{27}$ CEREC ile üretilen restorasyonların klinik başarı oranının ilk 5 yılda yaklaşık \%97 ve 10 yılda \%90 olduğunu bildirmiştir.

Çalışmamızda 1. yılın sonunda nano seramik rezin inley restorasyonlar istatistiksel olarak anlamlı olmamasına rağmen yüzey parlaklığı açısından direkt kompozit rezin restorasyonlardan daha çok sayıda 1 skoru alarak daha iyi performans göstermişlerdir. Çetin ve Ünlü, ${ }^{28}$ direkt ve indirekt kompozit rezin restorasyonları karşılaştırdıkları klinik çalışmalarında, yüzey özellikleri açısından indirekt restorasyonlardaki daha başarılı sonucu bu materyallerin aşınma dirençlerinin daha yüksek olmasına bağlamışlardır. Diğer yandan, çalışmamızla benzer olarak, ScheibenbogenFuchsbrunner ve ark., ${ }^{22}$ direkt ve indirekt farklı posterior kompozit rezin sistemleriyle yaptıkları 2 yıllık klinik çalışmalarında yüzey parlaklığı açısından istatistiksel olarak anlamlı bir fark bulmamışlardır. Mendonça ve ark. ${ }^{20}$ direkt kompozit rezin restorasyonlar ile indirekt kompozit rezin inleyleri karşılaştırdıkları 1 yıllık klinik çalışmalarında, yüzey özellikleri açısından gruplar arasında istatistiksel olarak anlamlı bir fark bulmamışlardır. Aynı şekilde, Lange ve Pfeiffer, ${ }^{25}$ seramik inleyler ile direkt kompozit rezin restorasyonları karşılaştırdıkları çalışmalarında, yüzey özellikleri açısından gruplar arasında istatistiksel olarak anlamlı bir fark bulmamıştır. Çalışmamızda 6. aydan sonra kompozit rezin restorasyon grubundaki 4 restorasyonda yüzey parlaklığında azalma görülmüştür. Bunun sebebi olarak kompozit rezin restorasyonların yüzey aşınmalarına daha yatkın olmaları ve sadece ağız içinde parlatılabilmeleri gösterilebilir.

Çalışmamız CAD/CAM sistemleriyle hazırlanan nano seramik rezin inley restorasyonların kısa dönemdeki klinik performanslarının tahmin edilmesinde faydalı olmuştur. Literatürde henüz nano seramik rezin blokların kullanıldığı bir klinik çalışma bulunmamakla birlikte, çalışmamızın 1 yıllık kontrol dönemine sahip olması çalışmamızın sınırlamaları arasında yer almaktadır. Dental restorasyonların klinik performansının değerlendirilmesinde 5 yıla kadar orta dönem ve 5 yıl üzerinde uzun dönem takipli klinik çalışmalara ihtiyaç vardır. Çalışmamızda da restorasyonların en az 5 yıl süreyle takibi planlanmaktadır.

\section{SONUÇLAR}

$\mathrm{Bu}$ çalışmanın sınırlamaları dahilinde, 1 yıllık sonuçlarımıza göre estetik, fonksiyonel ve biyolojik kriterler açısından çalışmada değerlendirilen nano seramik rezin inley restorasyonlar ile nanohibrit direkt kompozit rezin restorasyonlar arasında anlamlı bir fark gözlenmemiştir. CAD/CAM ile hazırlanan nano seramik rezin inley restorasyonlar 1 yıl sonunda direkt kompozit rezin restorasyonlar kadar başarılı bulunmuştur.

\section{KAYNAKLAR}

1. Keshvad A, Hooshmand T, Asefzadeh F, Khalilinejad $F$, Alihemmati $M$, Van Noort $R$. Marginal gap, internal fit and fracture load of leucite-reinforced ceramic inlays fabricated by CEREC inLab and hot-pressed techniques. J Prosthodont 2011;20:535-40.

2. Öztürk Ö. Seramik inley restorasyonlar. Atatürk Üniv Diş Hek Fak Derg 2015;10:118-24.

3. Şahin E, Aktaş DG, Özcan DN, Aydın DDH, Akça K. Restoratif diş hekimliğinde CAD/CAM klinik uygulamalar: Sirona CEREC sistemi. Hacettepe Dis Hek Fak Derg 2009;33:34-40.

4. Fasbinder DJ. Clinical performance of chairside CAD/CAM restorations. J Am Dent Assoc 2006;137:22S-31S.

5. Martin N, Jedynakiewicz N. Clinical performance of CEREC ceramic inlays: a systematic review. Dent Mater 1999;15:54-61.

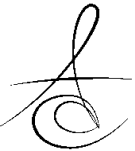


Atatürk Üniv. Diş Hek. Fak. Derg.

J Dent Fac Atatürk Uni

Cilt:27, Sayı:2, Yıl: 2017, Sayfa, 79-87

6. Brauner AW, Bieniek KW. Seven years of clinical experience with the CEREC inlay system. CAD/CAM in aesthetic dentistry: CEREC. 1996;10:217-228.

7. Chabouis HF, Faugeron VS, Attal J-P. Clinical efficacy of composite versus ceramic inlays and onlays: A systematic review. Dent Mater 2013;29:1209-18.

8. Koller M, Arnetzl G, Holly L, Arnetzl G. Lava ultimate resin nano ceramic for CAD/CAM: customization case study. Int J Comput Dent 2011; 15:159-64.

9. Fleming M. In-office milling: maximizing aesthetics and efficiency. Dent Today 2012;31:140-2.

10. https://www.e-calib.info/ Erişim: 23.08.2016.

11. Kim J, Shin W. How to do random allocation (randomization). Clin Orthop Surg. 2014;6:103-9.

12. Hickel R, Peschke A, Tyas M, Mjör I, Bayne S, Peters M, Hiller KA, Randall R, Vanherle G, Heintze SD. FDI World Dental Federation - Clinical Criteria for the Evaluation of Direct and Indirect Restorations. Update and Clinical Examples. J Adhes Dent 2010;12:259-72.

13. Hickel R, Dasch W, Mehl A, Kremers L. CAD/CAMFillings of the future? Int Dent J 1997;47:247-58.

14. Mehl A, Hickel R. A new optical 3D-scanning system for CAD/CAM technology. Int J Comput Dent 1999;2:129-36.

15. Alt V, Hannig M, Wöstmann B, Balkenhol $M$. Fracture strength of temporary fixed partial dentures: CAD/CAM versus directly fabricated restorations. Dent Mater 2011;27:339-47.

16. Stawarczyk B, Ender A, Trottmann A, Özcan M, Fischer J, Hämmerle $\mathrm{CH}$. Load-bearing capacity of CAD/CAM milled polymeric three-unit fixed dental prostheses: Effect of aging regimens. Clin Oral Investig 2012;16:1669-77.

17. Stawarczyk B, Krawczuk A, Ilie N. Tensile bond strength of resin composite repair in vitro using different surface preparation conditionings to an aged CAD/CAM resin nanoceramic. Clin Oral Investig 2015;19(2):299-308.

18. Stawarczyk B, Özcan M, Schmutz F, Trottmann A, Roos $\mathrm{M}$, Hämmerle $\mathrm{CH}$. Two-body wear of monolithic, veneered and glazed zirconia and their corresponding enamel antagonists. Acta Odontol Scand 2013;71:102-12.

19. Arenholt-Bindslev D. Environmental aspects of dental filling materials. Eur J Oral Sci 1998; 106:713-20.
TUNAÇ, UZER ÇELİK, YAŞA

20. Mendonça JS, Neto RG, Santiago SL, Lauris J, Navarro M, de Carvalho RM. Direct resin composite restorations versus indirect composite inlays: oneyear results. J Contemp Dent Pract 2010;11:25-32.

21. Spreafico RC, Krejci I, Dietschi D. Clinical performance and marginal adaptation of class II direct and semidirect composite restorations over 3.5 years in vivo. J Dent 2005;33:499-507.

22. Scheibenbogen-Fuchsbrunner A, Manhart J, Kremers L, Kunzelmann K-H, Hickel R. Two-year clinical evaluation of direct and indirect composite restorations in posterior teeth. J Prosthet Dent 1999;82:391-7.

23. Cetin AR, Unlu N, Cobanoglu N. A five-year clinical evaluation of direct nanofilled and indirect composite resin restorations in posterior teeth. Oper Dent 2013;38:E31-E41.

24. Dukic W, Dukic O, Milardovic S, Delija B. Clinical evaluation of indirect composite restorations at baseline and 36 months after placement. Oper Dent 2010;35:156-64.

25. Lange R, Pfeiffer P. Clinical evaluation of ceramic inlays compared to composite restorations. Oper Dent 2009;34:263-72.

26. Fasbinder DJ, Dennison JB, Heys DR, Lampe K. The clinical performance of CAD/CAM-generated composite inlays. J Am Dent Assoc 2005;136:171423.

27. Fasbinder DJ. Clinical performance of chairside CAD/CAM restorations. J Am Dent Assoc 2006; 137:22S-31S.

28. Cetin AR, Unlu N. One-year clinical evaluation of direct nanofilled and indirect composite restorations in posterior teeth. Dent Mater J. 2009;28:620-6.

\section{Yazışma Adresi}

Ayşe Tuğçe TUNAÇ

İzmir Kâtip Çelebi Üniversitesi Diş Hekimliği Fakültesi Restoratif Diş Tedavisi A.D.

Aydınlık Evler Mahallesi, Cemil Meriç Caddesi, 6780 Sokak. No:48, 35640-Çiğli / İZMİR

Tel: +90 (232) 3254040

Fax: +90 (232) 3252535

E-mail: aysetugcetunac@hotmail.com 